\title{
Water-Soluble Benzazole Dyes Fluorescent by ESIPT: Structural Characterization, Photophysical Properties and Its Application as a Probe for Direct Staining of Helminths
}

\author{
Hélio L. Barros, ${ }^{\oplus a}$ Sandra M. T. Marques ${ }^{b}$ and Valter Stefani ${ }^{*}, a$ \\ ${ }^{a}$ Laboratório de Novos Materiais Orgânicos e Química Forense (LNMO-QF), Instituto de Química, \\ Universidade Federal do Rio Grande do Sul, Av. Bento Gonçalves, 9500, 91501-970 Porto Alegre-RS, Brazil \\ ${ }^{b}$ Laboratório de Helmintologia, Faculdade de Veterinária, Universidade Federal do Rio Grande do Sul, \\ Av. Bento Gonçalves, 9090, 91501-970 Porto Alegre-RS, Brazil
}

\begin{abstract}
A series of four water-soluble benzazole dyes that emit fluorescence by the excited state intramolecular proton transfer (ESIPT) mechanism were structurally characterized by Fourier transform infrared spectroscopy (FTIR), ${ }^{1} \mathrm{H}$ and ${ }^{13} \mathrm{C}$ nuclear magnetic resonance (NMR) attached proton test (APT) and mass spectrometry. Their photophysical properties were systematically studied by UV-absorption and fluorescence emission. Some photophysical parameters were obtained by semi-empirical PM3 and ZINDO methods, and related to experimental photophysical data. Changes in the absorption and fluorescence emission spectra as well as conformational equilibrium between different species were investigated in solvents of different polarities and under different $\mathrm{pH}$ conditions. These benzazole dyes emit dual fluorescence emission in the blue-orange region with a Stokes shift between $2617-12337 \mathrm{~cm}^{-1}$. In general, these dyes are potentially interesting for studies of biological systems in an aqueous environment due to the presence of groups that increase aqueous solubility and reactivity with biomolecules. The present dyes were successfully used as new probes by means of direct staining of larvae. The obtained results indicate that these fluorescent dyes permit a quick, easy and selective visualization of larvae.
\end{abstract}

Keywords: heterocyclic compounds, proton transfer, conformational equilibrium, fluorescence, helminths

\section{Introduction}

Heterocyclic benzazole compounds are of great synthetic interest because of their versatility and a variety of applications, such as the detection of latent fingermarks, ${ }^{1}$ their utility as laser dyes, ${ }^{2}$ UV photostabilizers ${ }^{3-5}$ and optical filters ${ }^{6,7}$ and, particularly, in studies on biological systems. ${ }^{8-12}$ The latter is largely influenced by their pharmacological activities, i.e., antiviral ${ }^{13}$ antibiotic, ${ }^{14}$ antifungal,${ }^{15}$ anticancer, ${ }^{16}$ antiparasitic, ${ }^{17}$ antimicrobial ${ }^{18}$ and anti-Parkinson's disease. ${ }^{19}$ However, many properties of these compounds in aqueous media are limited in some applications, particularly due to their poor aqueous solubility. ${ }^{20-22}$ We report here four benzazole dyes, namely HB-6, HB-7, HB-9 and HB-11, which incorporate hydrophilic groups to increase their aqueous solubility and reactivity with biomolecules. These compounds demonstrate excellent thermal, photochemical and

*e-mail: vstefani@iq.ufrgs.br photophysical stability. ${ }^{23-25}$ The large Stokes shift of these molecules, caused by the excited state intramolecular proton transfer (ESIPT) mechanism, is an important characteristic for biological applications because many biological systems show auto-fluorescence in the blue-green region. ${ }^{26}$

The ESIPT mechanism is a photo-induced process in which a proton is transferred from a proton donor $\left(-\mathrm{OH},-\mathrm{NH}_{2}\right)$ to a proton receptor $(-\mathrm{C}=\mathrm{O},-\mathrm{N}=)$ when they are nearby, ${ }^{27,28}$ see Figure 1. In the ground state, molecules that exhibit ESIPT exist exclusively in the enol conformer, which is stabilized by intramolecular hydrogen bonding. When the enol conformer (E1) is irradiated by UV light, it absorbs energy and gives rise to the excited enol conformer $\left(\mathrm{E} 1^{*}\right)$, which is rapidly converted to the excited keto tautomer (K1*), also known as the ESIPT form, by intramolecular proton transfer. Then, the excited keto tautomer $(\mathrm{K} 1 *)$ decays to the ground state (K1), thus emitting fluorescence. The keto tautomer (K1) is less stable than the enol conformer (E1), so it is regenerated into the initial enol conformer (E1) 
without any photochemical change. ${ }^{29,30}$ Evidence of other conformers in solution that can compete with those exhibiting ESIPT was experimentally observed through the solvatochromic effect and dual fluorescence emission (Figure 2).$^{31}$ Other conformers of benzazoles may exist in solution and compete with those exhibiting ESIPT. For example, in protic or polar solvents, an enol-cis open conformer (E2) can be observed. ${ }^{32}$ On the other hand, in non-polar solvent, the enol-trans conformer (E3) or the enol-trans open conformer (E4) can also be stabilized..$^{33,34}$

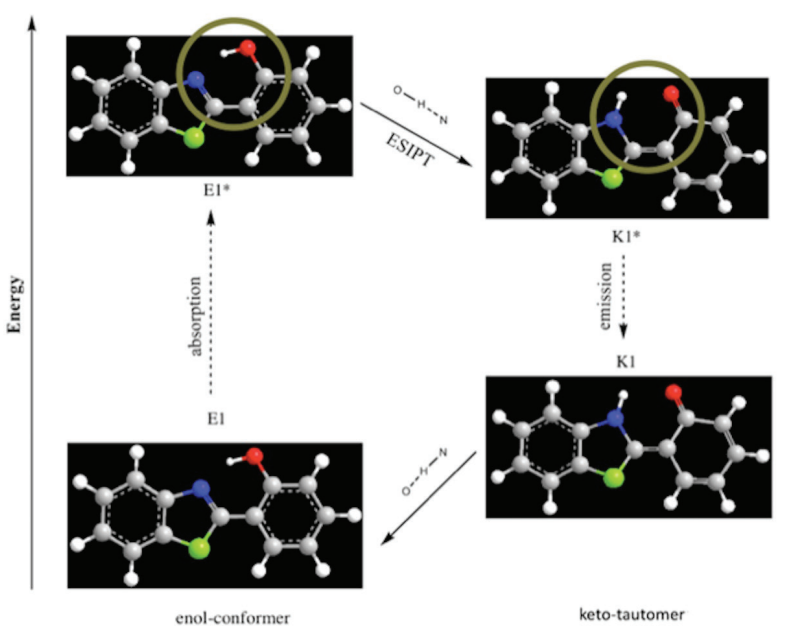

Figure 1. Photophysical pathways for ESIPT-exhibiting benzazole. E1 (enol conformer), K1 (keto tautomer), E1* (excited enol conformer) and K1* (excited keto tautomer or ESIPT form).

Infections with gastrointestinal helminths in ruminants and equines are caused by different types of parasites, most of them belonging to the superfamily Trichostrongyloidea. These infections incur important economic losses due to animal mortality and the expense of treatment with anthelmintics. The identification of parasite genera is difficult using stool tests because the eggs of various helminths have a similar appearance and size. So, it is necessary to cultivate the infective third stage larvae (L3) to identify the most pathogenic genera. The identification of larvae using currently available techniques is laborious and requires highly trained personnel. ${ }^{35}$ An easy and rapid method for the identification and differentiation of larvae species is proposed in this work, which consists of using these fluorescent dyes and epifluorescence microscopy for the staining and visualization of larvae.

\section{Experimental}

\section{Materials and measurements}

All reagents and solvents used in the synthesis and purification of the compounds were purchased from SigmaAldrich, Acros or Merck and were used without further purification. Deionized water was used for the preparation of dye solutions. Spectroscopic solvents (Merck and Deutero) were used to prepare samples for spectroscopic characterization. ${ }^{1} \mathrm{H}$ and ${ }^{13} \mathrm{C}$ nuclear magnetic resonance (NMR) spectra were obtained with a Varian INOVA-300 and Bruker Avance-400. Infrared (IR) spectra were obtained using a Mattson Galaxy Series 3000 FTIR in $\mathrm{KBr}$ and the mass spectra in a Shimadzu GCMS-QP20105 with a quadrupole analyzer. The absorption spectra were obtained using a Varian Cary-50 spectrometer and the fluorescence spectra were obtained with a Hitachi spectrometer model F-4500, using an excitation wavelength of $324 \mathrm{~nm}$. All the photophysical experiments were performed at room temperature $\left(25^{\circ} \mathrm{C}\right)$ and in a concentration range from $10^{-4}$ to $10^{-6} \mathrm{~mol} \mathrm{~L}^{-1}$. The fluorescence quantum yield of the dyes was determined using the single-point method. ${ }^{36,37}$ Anthracene with an excitation wavelength of $355 \mathrm{~nm}$
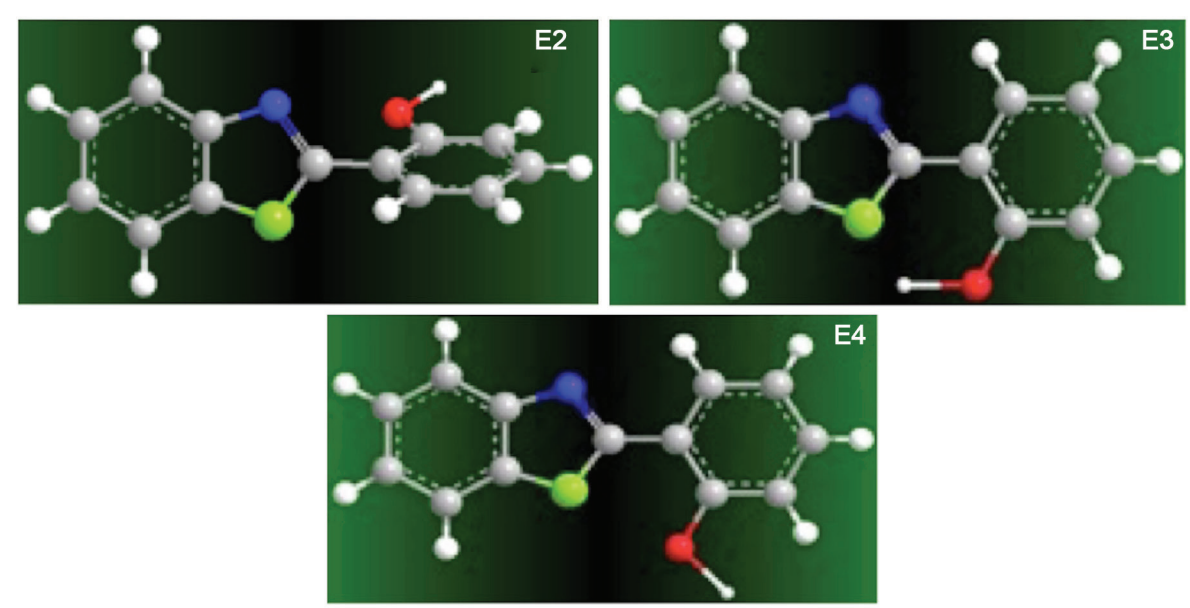

Figure 2. Different conformers of benzazoles in a solution that can compete with those exhibiting ESIPT. E2: enol-cis open conformer, E3: enol-trans conformer and E4: enol-trans open conformer. 


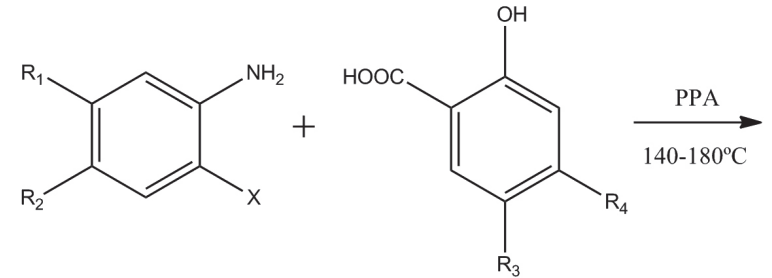

$$
\begin{aligned}
& \text { 1, X=O, } \mathrm{R}_{1}=\mathrm{H}, \mathrm{R}_{2}=\mathrm{H} \\
& \text { 2, X=S, } \mathrm{R}_{1}=\mathrm{H}, \mathrm{R}_{2}=\mathrm{H} \\
& \text { 3, X=O, } \mathrm{R}_{1}=\mathrm{H}, \mathrm{R}_{2}=\mathrm{CH}_{3} \\
& \text { 4, X=O, } \mathrm{R}_{1}=\mathrm{SO}_{3} \mathrm{H}, \mathrm{R}_{2}=\mathrm{H}
\end{aligned}
$$

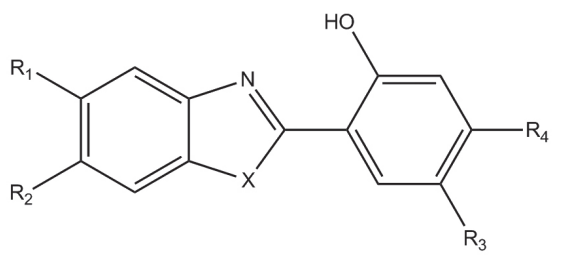

HB-6, $\mathrm{X}=\mathrm{O}, \mathrm{R}_{1}=\mathrm{H}, \mathrm{R}_{2}=\mathrm{H}, \mathrm{R}_{3}=\mathrm{SO}_{3} \mathrm{H}, \mathrm{R}_{4}=\mathrm{H}$ HB-7, $X=S, \mathrm{R}_{1}=\mathrm{H}, \mathrm{R}_{2}=\mathrm{H}, \mathrm{R}_{3}=\mathrm{SO}_{3} \mathrm{H}, \mathrm{R}_{4}=\mathrm{H}$ HB-9 X=O, $\mathrm{R}_{1}=\mathrm{H}, \mathrm{R}_{2}=\mathrm{CH}_{3}, \mathrm{R}_{3}=\mathrm{SO}_{3} \mathrm{H}, \mathrm{R}_{4}=\mathrm{H}$ HB-11, X=O, $\mathrm{R}_{1}=\mathrm{SO}_{3} \mathrm{H}, \mathrm{R}_{2}=\mathrm{H}, \mathrm{R}_{3}=\mathrm{NH}_{2}, \mathrm{R}_{4}=\mathrm{H}$

Scheme 1. Synthetic procedure for the preparation of water-soluble benzazole dyes.

$\left(\Phi_{\mathrm{F}} 0.29\right.$ in ethanol) was used as the reference. The measurements were performed in water ( $\mathrm{pH} 6)$, ethanol and ethyl acetate at $25^{\circ} \mathrm{C}$ with absorbance $<0.1$ (concentration of $1 \times 10^{-6} \mathrm{~mol} \mathrm{~L}^{-1}$ ) (Table S1 in the Supplementary Information (SI) section).

General procedure for the synthesis of the benzazole dyes HB-6, HB-7, HB-9 and HB-11

The general methodology for benzazole dye synthesis is presented in Scheme 1. The reaction consists of the condensation of substituted salicylic acid derivatives with ortho-substituted anilines in polyphosphoric acid with the temperature ranging from 140 to $180{ }^{\circ} \mathrm{C}$. These compounds were prepared by the present authors, and they are in patent pending at the National Institute of Intellectual Property. ${ }^{38}$ Some of them have been successfully used to reveal latent fingermarks on the sticky side of different types and colors of adhesive tape ${ }^{1}$ and for the visualization of Oxyuris equi eggs. ${ }^{8}$ These benzazole dyes are water-soluble and fluorescent in the blue-orange region when exposed to longwave UV light. Figure 3 shows the fluorescent dyes in the solid state under white light (Figure 3a) and ultraviolet light of $365 \mathrm{~nm}$ (Figure $3 b$ ), where we can see an intense fluorescence emission. Some sulfonated benzothiazole derivatives

(a)

$$
\text { HB-6 }
$$

HB-7

HB-9

HB-11

(b)
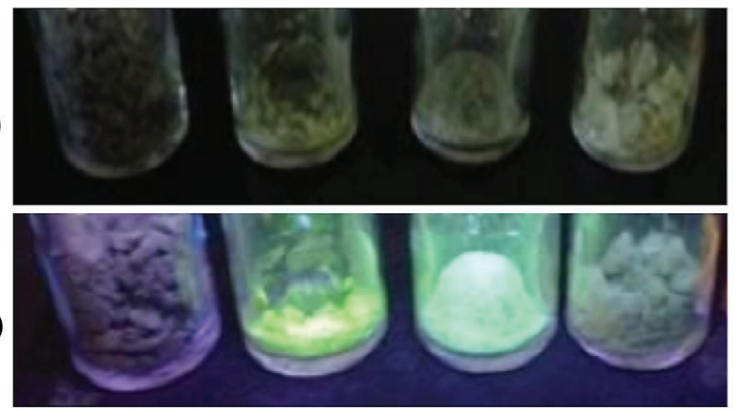

Figure 3. Images of HB-6, HB-7, HB-9 and HB-11 in the solid state (a) under white light and (b) under ultraviolet light of $365 \mathrm{~nm}$. were patented in 1970 by Freyermuth, ${ }^{39}$ using different methodology to introduce sulfonate group.

3-(Benzo[d]oxazol-2-yl)-4-hydroxybenzenesulfonic acid (HB-6)

Purple solid; yield 54\%; mp > $300{ }^{\circ} \mathrm{C} ;{ }^{1} \mathrm{H}$ NMR $\left(300 \mathrm{MHz}, \mathrm{DMSO}-d_{6}\right) \delta 8.00(\mathrm{dd}, J 7.9,1.7 \mathrm{~Hz}, 1 \mathrm{H})$, 7.87-7.78 (m, 2H), 7.49-7.42 (m, 2H), 7.07 (d, J 7.5 Hz, $1 \mathrm{H}), 7.02-6.95(\mathrm{~m}, 1 \mathrm{H}) ;{ }^{13} \mathrm{C}$ NMR attached proton test (APT) $\left(75 \mathrm{MHz}, \mathrm{DMSO}-d_{6}\right) \delta 163.10,159.67,149.20$, $140.1,134.23,128.40,126.02,125.38,119.59,119.20$, 118.31, 111.36, 111.09; FTIR (KBr) v / $\mathrm{cm}^{-1} 3500,3250$, 3000, 2325, 1650, 1500, 1250, 1120, 880, 750.

3-(Benzo[d]thiazol-2-yl)-4-hydroxybenzenesulfonic acid (HB-7)

Gray solid; yield $71 \%$; mp 157-160 ${ }^{\circ} \mathrm{C} ;{ }^{1} \mathrm{H}$ NMR (400 MHz, DMSO- $\left.d_{6}\right) \delta 8.48(\mathrm{~d}, J 2.1 \mathrm{~Hz}, 1 \mathrm{H}), 8.12$ (dd, $J 2.1,7.9 \mathrm{~Hz}, 2 \mathrm{H}), 7.63(\mathrm{dd}, J 8.5,2.2 \mathrm{~Hz}, 1 \mathrm{H}), 7.58-7.52$ (m, 1H), 7.49-7.42 (m, 1H), $7.03(\mathrm{~d}, J 8.5 \mathrm{~Hz}, 1 \mathrm{H})$; ${ }^{13} \mathrm{C}$ NMR APT (75 MHz, DMSO- $d_{6}$ ) $\delta 164.93,156.77$, $151.79,140.42,134.89,130.34,126.96,126.38,125.57$, 122.59, 122.51 117.75, 116.62; FTIR (KBr) $v / \mathrm{cm}^{-1} 3500$, 1625, 1500, 1020, 750 .

4-Hydroxy-3-(6-methylbenzo[d]oxazol-2-yl)benzenesulfonic acid (HB-9)

Gray solid; yield $16 \%$; mp $136-137{ }^{\circ} \mathrm{C}$; ${ }^{1} \mathrm{H}$ NMR (300 MHz, DMSO- $\left.d_{6}\right) \delta 7.98$ (dd, $\left.J 8.1,1.6 \mathrm{~Hz}, 1 \mathrm{H}\right), 7.70$ $(\mathrm{d}, J 8.1 \mathrm{~Hz}, 1 \mathrm{H}), 7.64-7.61(\mathrm{~m}, 1 \mathrm{H}), 7.55-7.46(\mathrm{~m}, 1 \mathrm{H})$, $7.26(\mathrm{dd}, J 8.8,0.7 \mathrm{~Hz}, 1 \mathrm{H}), 7.14-7.02(\mathrm{~m}, 2 \mathrm{H}) ;{ }^{13} \mathrm{C} \mathrm{NMR}$ APT $\left(75 \mathrm{MHz}, \mathrm{DMSO}-d_{6}\right) \delta 162.15,158.10,149.39$, 137.62, 136.45, 134.13, 127.71, 126.81, 120.34, 118.94, 117.51, 111.37, 110.80, 21.70; FTIR (KBr) v / $\mathrm{cm}^{-1} 3300$, 3000, 2900, 1725, 1500, 1250, 1040, 850, 750.

2-(5-Amino-2-hydroxyphenyl)benzo[d]oxazole-5-sulfonic acid (HB-11)

Gray solid; yield 54\%; mp > $300{ }^{\circ} \mathrm{C} ;{ }^{1} \mathrm{H}$ NMR 
(300 MHz, DMSO- $\left.d_{6}\right) \delta 7.86(\mathrm{t}, J 1.0 \mathrm{~Hz}, 1 \mathrm{H}), 7.81(\mathrm{~d}$, $J 2.7 \mathrm{~Hz}, 1 \mathrm{H}), 7.72(\mathrm{~d}, J 1.1 \mathrm{~Hz}, 2 \mathrm{H}), 7.41(\mathrm{dd}, J 8.9,2.7 \mathrm{~Hz}$, $1 \mathrm{H}), 7.19(\mathrm{~d}, J 8.8 \mathrm{~Hz}, 1 \mathrm{H}) ;{ }^{13} \mathrm{C}$ NMR APT $(100 \mathrm{MHz}$, DMSO- $\left.d_{6}\right) \delta 164.94,156.97,151.49,140.04,140.01$, 134.83, 130.39, 127.01, 126.39, 125.62, 122.51, 117.75, 116.74; FTIR (KBr) $v / \mathrm{cm}^{-1} 3400,3050,2600,1625,1400$, 1250, 1100, 1040, 775, 700, 600.

\section{Computational details}

Theoretical calculations were performed with Argus Lab software $4.01 .^{40}$ Final geometry optimization and energy of the highest occupied molecular orbital (HOMO) and lowest unoccupied molecular orbital (LUMO) were done with semi-empirical PM3 (NDDO) method and STO-3G basis set. Electronic transitions were calculated using ZINDO method and STO-6G basis set (in vacuum). The electron density and spatial orientation of the HOMO and LUMO molecular orbitals, and electrostatic potential (ESP) mapping were obtained using semi-empirical PM3 and ZINDO methods, respectively.

\section{Formulation of the staining solution}

For staining the larvae, a $3.3 \mathrm{mmol} \mathrm{L}^{-1}$ solution of the dye HB-11 was prepared by dissolving $100 \mathrm{mg}$ of the dye in $100 \mathrm{~mL}$ of distilled water. The mixture was stirred until the dye dissolved completely. When necessary, the mixture was heated or sonicated.

\section{General procedure for staining Trichostrongyloidea larvae}

The third stage larvae (L3) were obtained by the fecal coproculture method, ${ }^{41}$ which consists of mixing feces with sterile sawdust and distilled water, which is then incubated at $25-27^{\circ} \mathrm{C}$ for seven days. After that, the culture flask was filled with water to the brim. The flask was capped with a Petri dish and quickly inverted to avoid spilling the liquid and placed in saline solution at $45^{\circ} \mathrm{C}$ until half of the Petri dish was filled, resulting in the attraction of L3 larvae out of the flask by hydrotropism. After $2 \mathrm{~h}$, the liquid in the Petri dish was collected with a pipette and stored in a test tube in a refrigerator at $5{ }^{\circ} \mathrm{C}$ and, subsequently, analyzed by optical microscopy and epifluorescence.

The larvae were incubated in a glass flask with the fluorescent probe $\mathbf{H B}-\mathbf{1 1}$ at a concentration of $3.3 \mathrm{mmol} \mathrm{L}^{-1}$ for $1 \mathrm{~min}$ to $24 \mathrm{~h}$, at room temperature, and observed using an epifluorescence microscope with a UV filter and a low power $(10 x)$ and high power objective (40x). The larvae images were obtained with excitation from a mercury lamp. The sample of the larvae (not stained with the dye) was first analyzed by epifluorescence microscopy, but no autofluorescence was observed.

\section{Results and Discussion}

\section{Photophysical properties}

The UV-Vis absorption and fluorescence emission spectra of the dyes HB-6, HB-7, HB-9 and HB-11 were performed in solution $\left(10^{-5} \mathrm{~mol} \mathrm{~L}^{-1}\right)$ using solvents with different polarities. The data are shown in Figure 4. The relevant UV-Vis absorption data from these dyes are summarized in Table 1. The maximum absorption of these dyes in all solvents is located in the range of $317-338 \mathrm{~nm}$ and showed a slight dependence on the solvent polarity (about $4 \mathrm{~nm}$ ). The HB-7 and HB-11 dyes showed higher wavelengths of maximum absorption compared to the other dyes (about $12 \mathrm{~nm}$ ). The HB-7 behavior can be explained by the better electron delocalization allowed by the sulfur atom in relation to the oxygen located on the azole ring. For HB-11, the presence of the amine group located on benzene ring opposite to the oxazole ring enhanced electron donating effect. The influence of donor and acceptor groups on other benzazole was related by Rodembusch et al..$^{29}$ and Padalkar et al..$^{42}$ They found that electron donor groups present on oxazole ring accelerate the flow of electron from donor to acceptor and cause red shifted absorption, as

Table 1. Absorption data for the benzazole dyes HB-6, HB-7, HB-9 and HB-11

\begin{tabular}{lccc}
\hline \multirow{2}{*}{ Dye } & Solvent & \multicolumn{2}{c}{ UV-Vis absorption } \\
\cline { 3 - 4 } & & $\lambda_{\max } / \mathrm{nm}$ & $\varepsilon_{\max } /\left(\times 10^{4} \mathrm{~L} \mathrm{~mol}^{-1} \mathrm{~cm}^{-1}\right)$ \\
\hline \multirow{2}{*}{ HB-6 } & water & 317 & 3.59 \\
& methanol & 324 & 3.41 \\
& ethanol & 319 & 4.67 \\
& ethyl acetate & 318 & 6.90 \\
\hline \multirow{3}{*}{ HB-7 } & water & 329 & 5.87 \\
& methanol & 331 & 4.20 \\
& ethanol & 332 & 5.18 \\
HB-9 & ethyl acetate & 333 & 4.50 \\
& water & 320 & 3.59 \\
& methanol & 321 & 5.00 \\
\hline \multirow{4}{*}{ HB-11 } & ethanol & 321 & 7.18 \\
& ethyl acetate & 321 & 5.60 \\
\hline \multirow{2}{*}{$*$} & water & 329 & 3.81 \\
& methanol & 332 & 4.25 \\
& ethanol & 338 & 4.54 \\
& ethyl acetate & 333 & 5.65 \\
\hline
\end{tabular}

$\lambda_{\max }:$ maximum absorption wavelength; $\varepsilon$ : molar absorptivity values. 



Figure 4. Normalized absorption and fluorescence emission spectra of HB-6, HB-7, HB-9 and HB-11 in solvents with different polarities (excitation wavelength $324 \mathrm{~nm}$ ). 
observed by us. The photophysical behavior is also usually related to the conformational equilibrium in solution in the ground state. ${ }^{43-45}$ All molar absorptivity values $(\mathcal{E})$ are on the order of $10^{4} \mathrm{~L} \mathrm{~mol}^{-1} \mathrm{~cm}^{-1}$, as expected for $\pi-\pi^{*}$ transitions.

The fluorescence emission spectra were obtained using an excitation wavelength of $324 \mathrm{~nm}$ (wavelength of maximum absorbance of these dyes). The relevant fluorescence emission data from these derivatives are summarized in Table 2. As expected for compounds which exhibit ESIPT, these derivatives exhibited dual fluorescence emission. ${ }^{29}$ The ESIPT mechanism is highly dependent on the polarity of the solvent, and thus the intensity of the two bands varies, dependent on the polarity of the solvent used. As shown in Figure 1, in the ground state enol conformer (E1) absorbs UV radiation, leading to the singlet excited state enol (E1*), which tautomerizes to the excited state keto tautomer $(\mathrm{K} 1 *)$. This conversion is responsible for energy loss with a large Stokes shift, and the excited keto tautomer decays to the ground state (K1), thereby emitting fluorescence. The excited enol can also decay to the ground state, without losing energy, via intramolecular proton transfer, thereby emitting fluorescence. The single red-shifted (higher wavelength) and blue-shifted (shorter wavelength) emission bands that appear in almost all fluorescence emission spectra are ascribed to the excited ceto tautomer (ESIPT band) and the excited enol conformer (normal band), respectively. Other conformational species that can be better stabilized in the excited state in the solvent were also related by Krishnamoorthy and Dogra ${ }^{46,47}$ for similar benzazole compounds.

The HB-7 dye in ethyl acetate, although seemed to be an exception, showed only one emission band ascribed to the ceto band, which is originated from excited state intramolecular proton transfer mechanism.

Despite these dyes have a similar chemical structures, they behaved independently, which indicated the photophysical behavior is not always directly related to the structures, or even solvents with similar polarities, as also observed by Dick et al. ${ }^{48}$

The Stokes shifts of these dyes were in the range of 2617-8038 and 8024-12337 $\mathrm{cm}^{-1}$ for the enol conformer and the keto tautomer, respectively. These values are summarized in Table 2 and are consistent with compounds that undergo ESIPT.

In order to understand the electronic transitions of these benzazole dyes, semi-empirical calculations on electronic absorption spectra in vacuum was performed using ZINDO method. The calculated energy of electronic transitions, assignment of the molecular orbital involved in the electronic transitions, and oscillator strength are listed in Table 3. The maximum observed absorbance of dyes, HB-6, HB-7, HB-9 and HB-11 are located about 320,

Table 2. Fluorescence emission data for the benzazole dyes HB-6, HB-7, HB-9 and HB-11

\begin{tabular}{|c|c|c|c|c|c|c|}
\hline \multirow{3}{*}{ Dye } & \multirow{3}{*}{ Solvent } & \multicolumn{4}{|c|}{ Fluorescence emission } & \multirow{3}{*}{$\Phi_{\mathrm{F}}$} \\
\hline & & \multicolumn{2}{|c|}{ Enol-form } & \multicolumn{2}{|c|}{ Keto-form } & \\
\hline & & $\lambda_{\max } / \mathrm{nm}$ & $\Delta \lambda_{\mathrm{ST}} / \mathrm{cm}^{-1}$ & $\lambda_{\max } / \mathrm{nm}$ & $\Delta \lambda_{\mathrm{ST}} / \mathrm{cm}^{-1}$ & \\
\hline \multirow{4}{*}{ HB-6 } & water & 365 & 4148 & 470 & 10269 & 0.026 \\
\hline & methanol & 364 & 3392 & 471 & 9633 & - \\
\hline & ethanol & 429 & 8038 & 526 & 12337 & 0.103 \\
\hline & ethyl acetate & 426 & 7862 & 510 & 11839 & 0.329 \\
\hline \multirow{4}{*}{ HB-7 } & water & 369 & 3295 & 449 & 8123 & 0.086 \\
\hline & methanol & 379 & 3826 & - & - & - \\
\hline & ethanol & 424 & 6536 & 503 & 10240 & 0.102 \\
\hline & ethyl acetate & - & - & 464 & 8478 & 0.295 \\
\hline \multirow{4}{*}{ HB-9 } & water & 423 & 7609 & 499 & 11209 & 0.119 \\
\hline & methanol & 366 & 3830 & 473 & 10071 & - \\
\hline & ethanol & 430 & 7897 & 495 & 10951 & 0.065 \\
\hline & ethyl acetate & 425 & 7624 & 508 & 11468 & 0.176 \\
\hline \multirow{4}{*}{ HB-11 } & water & 360 & 2617 & 447 & 8024 & 0.106 \\
\hline & methanol & 420 & 6311 & 511 & 10551 & - \\
\hline & ethanol & 372 & 2704 & 489 & 9136 & 0.122 \\
\hline & ethyl acetate & 449 & 7758 & 508 & 10345 & 0.180 \\
\hline
\end{tabular}

$\lambda$ : wavelength; $\Phi_{\mathrm{F}}$ : fluorescence quantum yield. 
331, 321 and $333 \mathrm{~nm}$, respectively, while the maximum absorbance calculated appeared at 329, 328, 335 and $340 \mathrm{~nm}$, respectively. These bands are due to transition between HOMO and LUMO and characterized by the lowest electronic transitions energy and by the highest oscillator strength value, as can be seen in Table 3 . The other higher electronic transitions are also shown in Table 3 , with their respective orbitals involved.

The good agreement between the theoretical and experimental was observed for all dyes, although theoretical calculation used did not take into account the effect of the solvent.

\section{Frontier molecular orbitals (HOMO and LUMO)}

The HOMO represents the capacity of the molecule to cede an electron, while LUMO represents the capacity to accept electron. They are the principal orbitals taking part in chemical reaction and chemical stability. ${ }^{49}$ The HOMO and LUMO orbitals can also determine the reactive site and the way by which the molecule interacts with other species. ${ }^{50,51}$

Table S2 (SI section) shows the calculated value of HOMO and LUMO energy, the energy gap between
HOMO and LUMO, the molecular hardness ( $\eta$ ) and other physicochemical parameters as the total energy of geometry structure optimization and heat of formation obtained by PM3 semi-empirical method. The results show energy gap values between 7.32 and $8.13 \mathrm{eV}$. These values are higher than energy gap obtained of other benzazole derivatives by density functional theory (DFT), where energy gap observed is from 4.23 to $4.43 \mathrm{eV}^{52}$

Figure 5 shows a comparison between the electron density of HOMO and LUMO, and electrostatic potential of the benzazole dyes synthesized. The electron densities are similar in general for the related structures. However, as expected for HOMO orbital of HB-11, the presence of a strong attractant group (sulfonic) removes the electronic density in the benzazole moiety. This result is also evidenced by the analysis of electrostatic potential (ESP) (Figure 5). In all cases, HOMO is localized orthogonal to the plane of the molecule and it is a bonding molecular orbital $(\pi)$, while LUMO is also orthogonal to the plane of the molecule, but it is non-bonding molecular orbital $\left(\pi^{*}\right)$. The electron density and spatial orientation of the HOMO and LUMO molecular orbitals show that the transition/excitation occurs between them and they are $\pi-\pi^{*}$ type. The ESIPT is associated to

Table 3. Theoretical and experimental electronic absorption spectrum of benzazole dyes

\begin{tabular}{|c|c|c|c|c|c|}
\hline \multirow{2}{*}{ Dye } & \multicolumn{2}{|c|}{ Energy } & \multirow{2}{*}{$\begin{array}{c}\text { Oscillator } \\
\text { strength / a.u. }\end{array}$} & \multirow{2}{*}{ State dipole / debye } & \multirow{2}{*}{ Electronic transition } \\
\hline & Calculated (calcd. / nm) / $\mathrm{cm}^{-1}$ & Experimental ${ }^{\mathrm{a}} / \mathrm{nm}$ & & & \\
\hline \multirow{7}{*}{ HB-6 } & $30436.1(328.6)$ & \multirow{7}{*}{320} & 0.6322 & 12.2157 & $\mathrm{HOMO} \rightarrow \mathrm{LUMO}$ \\
\hline & $34071.5(293.5)$ & & 0.0124 & 8.1979 & HOMO-2 $\rightarrow$ LUMO \\
\hline & $35099.9(284.9)$ & & 0.0749 & 9.7427 & $\mathrm{HOMO} \rightarrow \mathrm{LUMO}+5$ \\
\hline & 37374.8 (267.6) & & 0.0083 & 11.3410 & HOMO-8 $\rightarrow$ LUMO \\
\hline & 37891.3 (263.9) & & 0.0532 & 9.9325 & $\mathrm{HOMO}-2 \rightarrow \mathrm{LUMO}+2$ \\
\hline & $39600.0(252.5)$ & & 0.0114 & 4.4185 & $\mathrm{HOMO}-4 \rightarrow \mathrm{LUMO}+2$ \\
\hline & $39879.2(250.8)$ & & 0.1346 & 10.9064 & $\mathrm{HOMO}-3 \rightarrow \mathrm{LUMO}+2$ \\
\hline \multirow{7}{*}{ HB-7 } & $30446.1(328.0)$ & \multirow{7}{*}{331} & 0.6967 & 12.6398 & $\mathrm{HOMO} \rightarrow \mathrm{LUMO}$ \\
\hline & $34069.1(293.5)$ & & 0.0057 & 11.0889 & HOMO-8 $\rightarrow$ LUMO \\
\hline & 34108.7 (293.2) & & 0.0094 & 9.3099 & HOMO-2 $\rightarrow$ LUMO \\
\hline & $34553.5(289.4)$ & & 0.0810 & 10.4763 & $\mathrm{HOMO} \rightarrow \mathrm{LUMO}+5$ \\
\hline & $37938.9(263.6)$ & & 0.0546 & 11.2274 & $\mathrm{HOMO}-2 \rightarrow \mathrm{LUMO}+2$ \\
\hline & $39640.7(252.3)$ & & 0.0037 & 3.3843 & $\mathrm{HOMO}-4 \rightarrow \mathrm{LUMO}+2$ \\
\hline & $39893.4(250.7)$ & & 0.1169 & 12.1311 & HOMO-3 $\rightarrow$ LUMO +2 \\
\hline \multirow{7}{*}{ HB-9 } & $29898.6(334.5)$ & \multirow{7}{*}{321} & 0.5853 & 13.7381 & $\mathrm{HOMO} \rightarrow \mathrm{LUMO}$ \\
\hline & $33770.3(296.1)$ & & 0.0033 & 8.7539 & HOMO-2 $\rightarrow$ LUMO \\
\hline & $34825.0(287.2)$ & & 0.1081 & 11.2667 & HOMO-1 $\rightarrow$ LUMO \\
\hline & $39372.9(264.1)$ & & 0.0519 & 10.9843 & $\mathrm{HOMO}-2 \rightarrow \mathrm{LUMO}+2$ \\
\hline & $39372.9(254.0)$ & & 0.0177 & 16.8282 & HOMO-1 $\rightarrow$ LUMO \\
\hline & $39607.2(252.5)$ & & 0.0061 & 4.3602 & $\mathrm{HOMO}-4 \rightarrow \mathrm{LUMO}+2$ \\
\hline & $39865.7(250.8)$ & & 0.1864 & 11.8234 & $\mathrm{HOMO}-3 \rightarrow \mathrm{LUMO}+2$ \\
\hline \multirow{6}{*}{ HB-11 } & $29387.9(340.3)$ & \multirow{6}{*}{333} & 0.4371 & 12.4910 & $\mathrm{HOMO} \rightarrow \mathrm{LUMO}$ \\
\hline & $33569.8(297.9)$ & & 0.2624 & 11.1970 & HOMO-1 $\rightarrow$ LUMO \\
\hline & $35003.3(285.7)$ & & 0.1761 & 10.3931 & HOMO- $1 \rightarrow$ LUMO +1 \\
\hline & $37489.1(266.7)$ & & 0.0065 & 20.0053 & $\mathrm{HOMO}-1 \rightarrow \mathrm{LUMO}+2$ \\
\hline & $39322.3(254.3)$ & & 0.0630 & 6.9459 & $\mathrm{HOMO}-2 \rightarrow \mathrm{LUMO}+2$ \\
\hline & $40020.1(249.9)$ & & 0.0192 & 6.5402 & $\mathrm{HOMO}-4 \rightarrow \mathrm{LUMO}+2$ \\
\hline
\end{tabular}

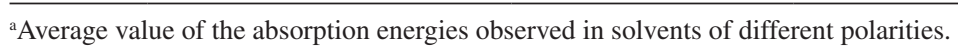


the change in electronic density, with the transfer of certain quantities of charges between the donor and the proton acceptor, after electronic excitation. ${ }^{53,54}$ The delocalization of the electron density in the pz orbital on the nitrogen atom of the azole ring and of the oxygen of the hydroxyl group is indicative of the change of basicity and acidity, which confirms the occurrence of ESIPT mechanism in these dyes, as observed in the experimental data.

ESP mapping is very useful to explore the reactivity of organic compounds. It has been applied successfully to understand and determine the nucleophilic as well as electrophilic sites in molecules. ${ }^{55}$ The nucleophilic and electrophilic sites of the molecule are expressed in term of different surface color, where the red color expresses an electron rich site (it is related to electrophilic reactivity), whereas white expresses an electron deficient site (it is related to nucleophilic reactivity). As can be seen in Figure 5, it is clear that electronic density in all dyes is concentrated on the oxygen atoms of the sulfonic and hydroxyl groups as well as in the heteroatoms of the azole ring. On the other hand, the benzene rings attached with sulfonic group are electron deficient sites, due to electron withdrawing nature of the substituent group.

The numerous applications of the benzazole dyes, especially in biological studies, underscore the need for a description of the fluorescence properties in aqueous solution, in particular, a description of the effects of $\mathrm{pH}$ and concentration. We believe that it can improve understanding of some phenomena related to the photoaffinity labeling of biological systems and their use as $\mathrm{pH}$ indicators.
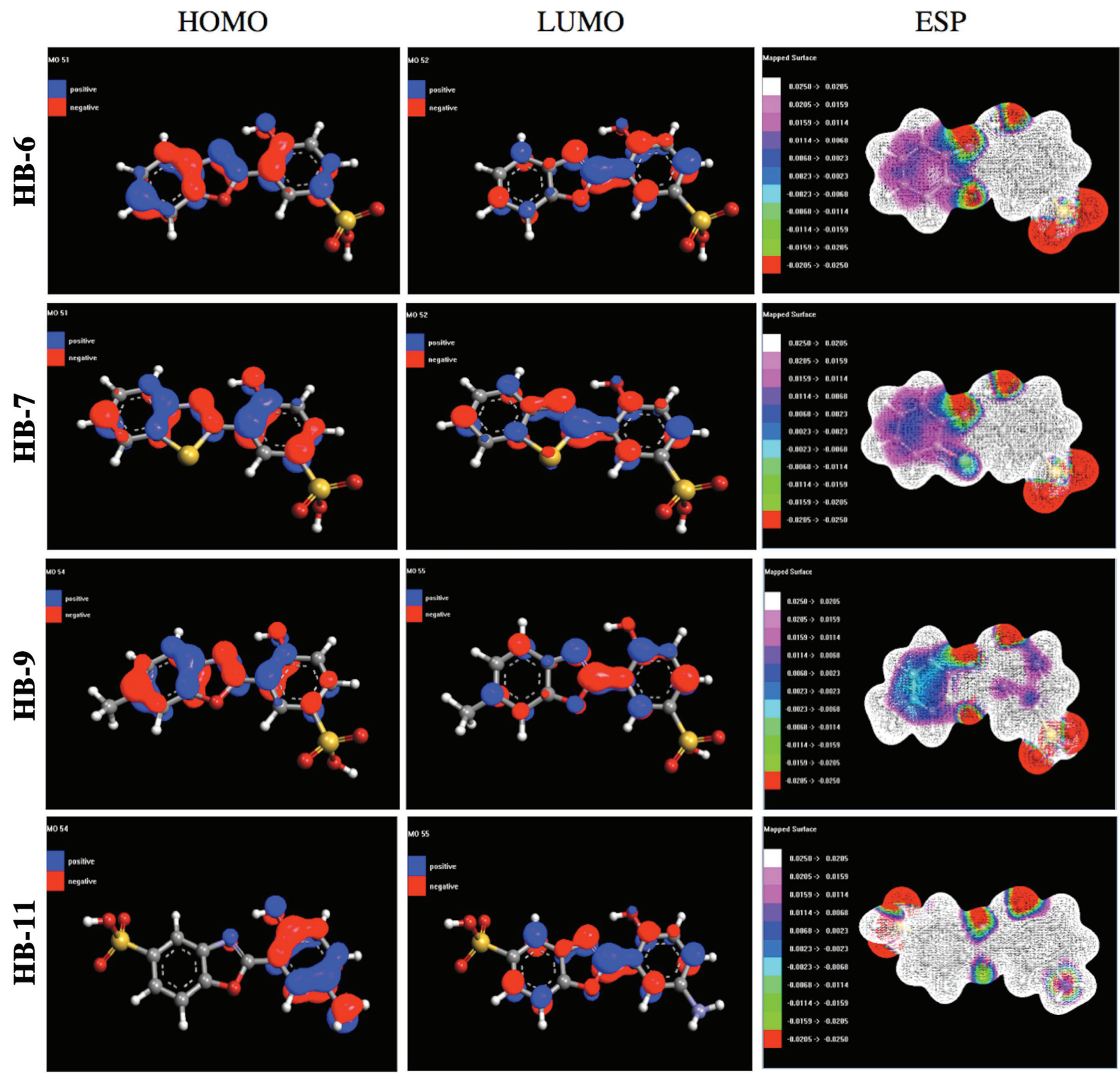

Figure 5. Electron density of frontier molecular orbitals obtained by PM3 method (the blue and red colors indicate opposite signals of the wave function) and electrostatic potential distribution obtained by ZINDO method ( $\mathrm{red}=$ larger electron density and white $=$ smaller electron density). 


\section{Concentration effect on fluorescence intensity}

Figure 6 shows the fluorescence emission spectra obtained using concentrations in the range of $10^{-6}$ to $10^{-4}$ mol L-1 for the dyes in aqueous solution with an excitation wavelength of $324 \mathrm{~nm}$. As expected, the florescence intensity increased with increased concentration as more molecules were absorbing light. This result indicates that, in this concentration range, no significant fluorescence quenching was observed. A plot of the maximum fluorescence intensity as a function of the dye concentration is shown in Figure S1 (SI section). The HB-9 dye showed higher fluorescence intensity compared to the other dyes in the same concentration range. In contrast, HB-6 required a higher concentration to achieve the same fluorescence intensity as HB-7 and HB-11.


\section{Dependence absorption and fluorescence intensity on $\mathrm{pH}$}

In order to determine the effect of $\mathrm{pH}$ on the photophysical properties, the absorbance and fluorescence emission were measured for each dye in a $\mathrm{pH}$ range from 2 to 12 and at a concentration of $3.2 \times 10^{-5} \mathrm{~mol} \mathrm{~L}^{-1}$ in aqueous solution (Figure 7, Figures S2 and S3 in SI section). The $\mathrm{pH}$ of the aqueous dye solutions was adjusted by dropwise addition of hydrochloric acid $\left(1 \mathrm{~mol} \mathrm{\textrm {L } ^ { - 1 } )}\right.$ or sodium hydroxide $\left(0.5 \mathrm{~mol} \mathrm{~L}^{-1}\right)$, and then the fluorescence intensity was measured as a function of $\mathrm{pH}$. Fluorescent compounds that possess acidic groups tend to be highly dependent on the $\mathrm{pH}$. We correlated the fluorescence intensity of these dyes with the $\mathrm{pH}$, and observed that fluorescence was significantly influenced by the $\mathrm{pH}$ conditions.

As shown in Figure 7 and Figure S2 (SI section), there was a change in the wavelength and/or the intensity
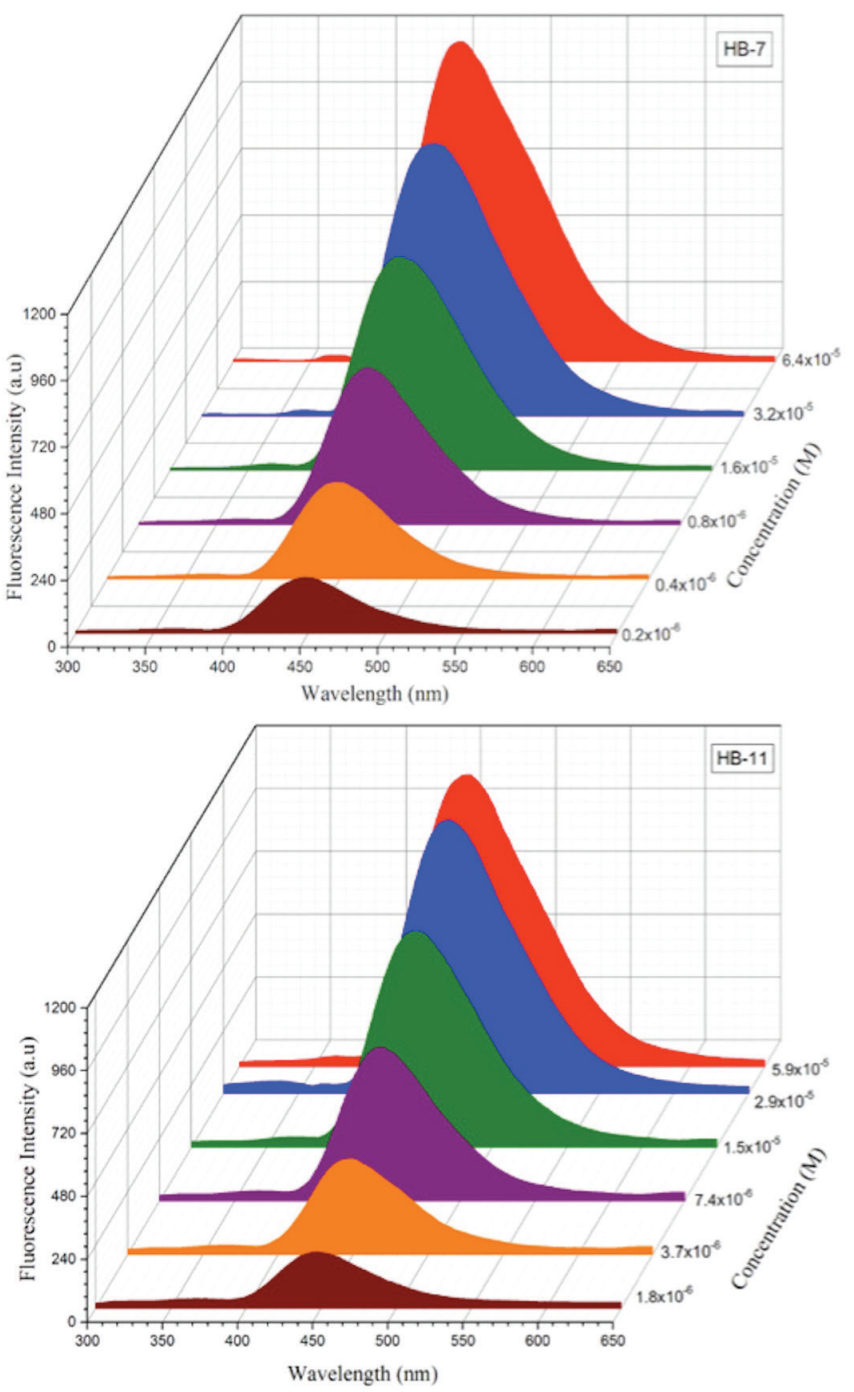

Figure 6. Fluorescence intensity spectra of HB-6, HB-7, HB-9 and HB-11 (in water) at different concentrations (excitation wavelength 324 nm). 



Figure 7. Fluorescence intensity spectra in $3.2 \times 10^{-5} \mathrm{~mol} \mathrm{~L}^{-1}$ aqueous solutions of HB-6, HB-7, HB-9 and $\mathbf{H B}-11$ at different $\mathrm{pH}$ levels (recorded at room temperature and an excitation wavelength of $324 \mathrm{~nm}$ ).

of fluorescence when the $\mathrm{pH}$ was changed from 6 to 8 . HB-6 showed a considerable change in both wavelength and fluorescence intensity. HB-7 and HB-11 showed a large change in fluorescence intensity, but the maximum emission wavelength remained unchanged. In contrast, HB-9 showed a slight change in fluorescence intensity and a large change in the maximum emission wavelength (approximately $100 \mathrm{~nm}$ ). These results reveal that at least two species give rise to fluorescence emission. The absorption spectra showed similar behavior (Figure S3, SI section), where a change in the structure of the bands (wavelength and absorption intensity) was observed as a function of $\mathrm{pH}$, again indicating the existence of different species in acidic and alkaline environments. The absorbance spectrum of the compound HB-6, as observed in the fluorescence spectrum, showed only a variation in intensity above $\mathrm{pH}$ 8. HB-7 showed three absorbance
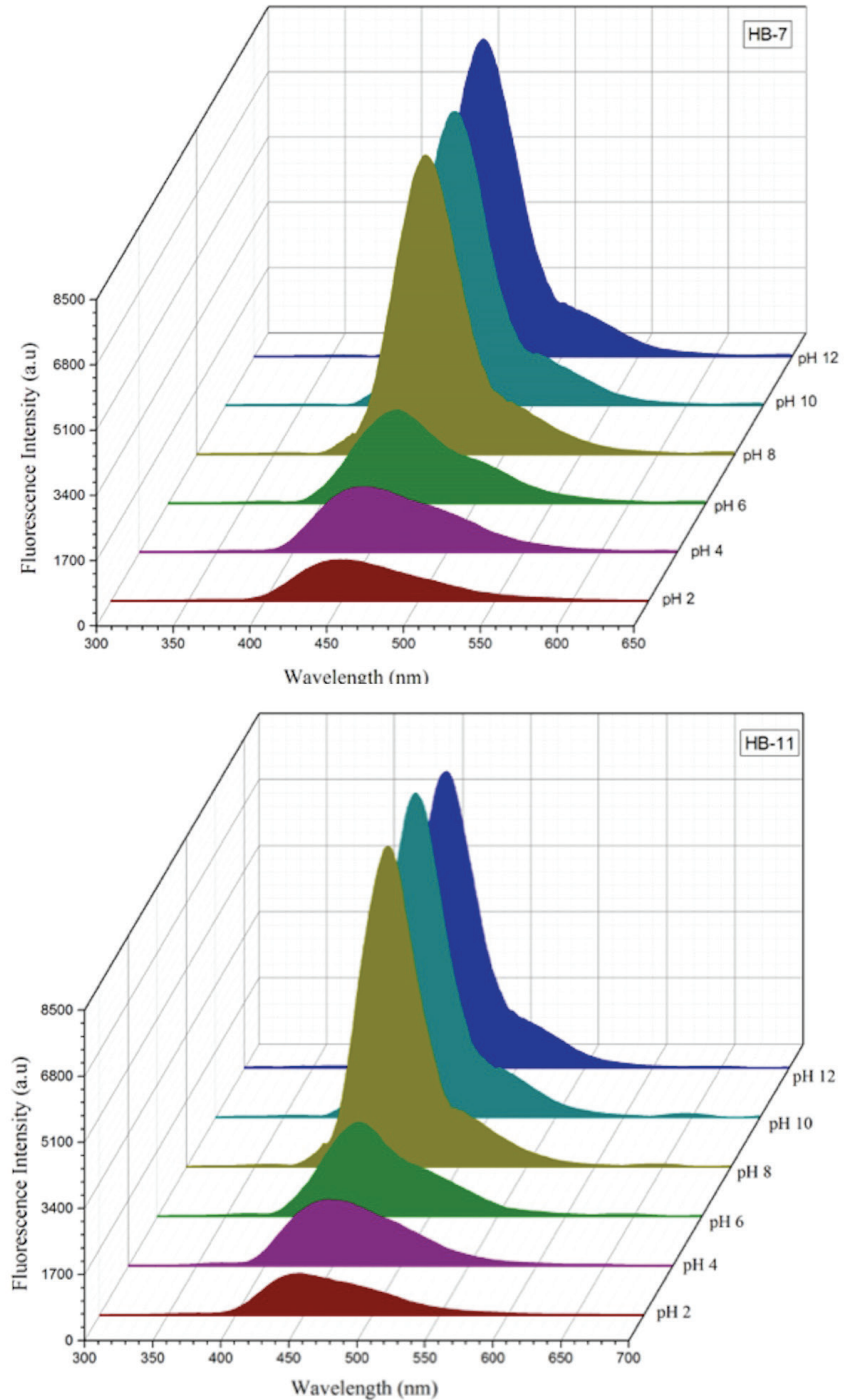

band profiles with an absorbance maximum at different wavelengths, depending on the $\mathrm{pH}$. The first profile, from $\mathrm{pH} 2$ to 4, had an absorbance maximum at $325 \mathrm{~nm}$. The second, up to $\mathrm{pH} 6$, had a lower absorbance intensity maximum at $325 \mathrm{~nm}$, while another band appeared at $375 \mathrm{~nm}$; this band intensified from $\mathrm{pH} 10$ to 12 . HB-9 showed similar results as HB-6, i.e., only a variation in the intensity of the absorbance band when the $\mathrm{pH}$ increased. HB-11 showed a similar result as HB-7, with three absorbance band profiles with maximum absorbance at $325 \mathrm{~nm}$ at $\mathrm{pH} 2$, a decrease in this band from $\mathrm{pH} 4$ to 6 , and the appearance of another band at $375 \mathrm{~nm}$, which intensified from $\mathrm{pH} 10$ to 12 . Additional studies that include theoretical calculations are in progress to identify the species responsible for the absorption and fluorescence emission at the studied $\mathrm{pH}$ levels. 


\section{Staining methodology}

In order to assess the ability of these dyes to stain larvae, HB-11 was incubated in complete culture medium at a concentration of $3.3 \mathrm{mmol} \mathrm{L}^{-1}$ and uptake was studied by epifluorescence microscopy at different time points ( 1 min to $24 \mathrm{~h}$ ). The fluorescence emitted by the larvae clearly confirmed that our molecules efficiently stain the larvae by penetrating the cell membrane. The fluorescence intensity of the stained larvae was influenced by the staining time. As shown in Figure 8, the fluorescence intensity after $24 \mathrm{~h}$ was higher than the intensity observed after 1 min of exposure to the dye solution. However, for the detection and diagnosis of larvae, 1 min of exposure was enough, making this a quick and easy method. Another advantage of this method is that it can be used with fluorescent dyes solubilized in water, which will stain biologic material without altering the morphology; moreover, this technique is environmentally safe. Many other dyes, currently used for staining biologic materials, use organic solvents alone or in aqueous mixtures, which may be combined with acids or bases in their formulation, preventing their use to study the morphology of biological material. Furthermore, the use of organic solvents is associated with an increased health risk for those who handle them frequently and therefore should be avoided. The high thermal, chemical and photochemical stability of these dyes as well as the low cost of their synthesis and purification make these new dyes a simple and versatile tool to study biological systems. The photostability was evaluated during the time that the larvae staining with the dye remained under excitation in the epifluorescence microscopy (20 min) and the storage time of the dye solution in the laboratory bench (1 year). Fluorescence was unchanged in these two circumstances. The dye solutions may be stored for long period of time without any degradation of the dyes. Figure 9 shows the optical and epifluorescence microscopy images of different regions of larvae stained with HB-11 for $24 \mathrm{~h}$. Similar results were obtained with HB-7 and HB-9.

We believe that the staining mechanism was likely via a chemical reaction or via electrostatic adsorption of the dye by proteins or other amino groups on the cell membrane, as we suggested for the development of latent fingerprints. ${ }^{1}$ In this study, we limited ourselves to showing the effectiveness of these dyes in staining larvae. Morphological studies and the differentiation of larvae species are still in progress and will be reported in due course.

\section{Conclusions}

In the present work, the synthesis of new water-soluble benzazole dyes and their characterization by FTIR, NMR $\left({ }^{1} \mathrm{H}\right.$ and ${ }^{13} \mathrm{C}$ APT), mass spectrometry, UV-Vis and fluorescence spectroscopic and spectrometric data were described. These dyes showed good photophysical stability in the course of analysis (20 min) and intense fluorescence emission in the blue-green region (364-526 nm). The


Figure 8. Epifluorescence microscopy pictures of different regions of larvae stained with HB-11 (concentration of $3.3 \mathrm{mmol} \mathrm{L}^{-1}$ ) for different periods of time, at low power (10x, top) and high power (40x, bottom), using a UV filter and a mercury lamp as a source of excitation. (a), (d) and (f): 1 min; (b): $10 \mathrm{~min}$; (c) and (e): $24 \mathrm{~h}$. Larvae are $2-8 \mathrm{~mm}$ long by $50-60 \mu \mathrm{m}$ wide. 

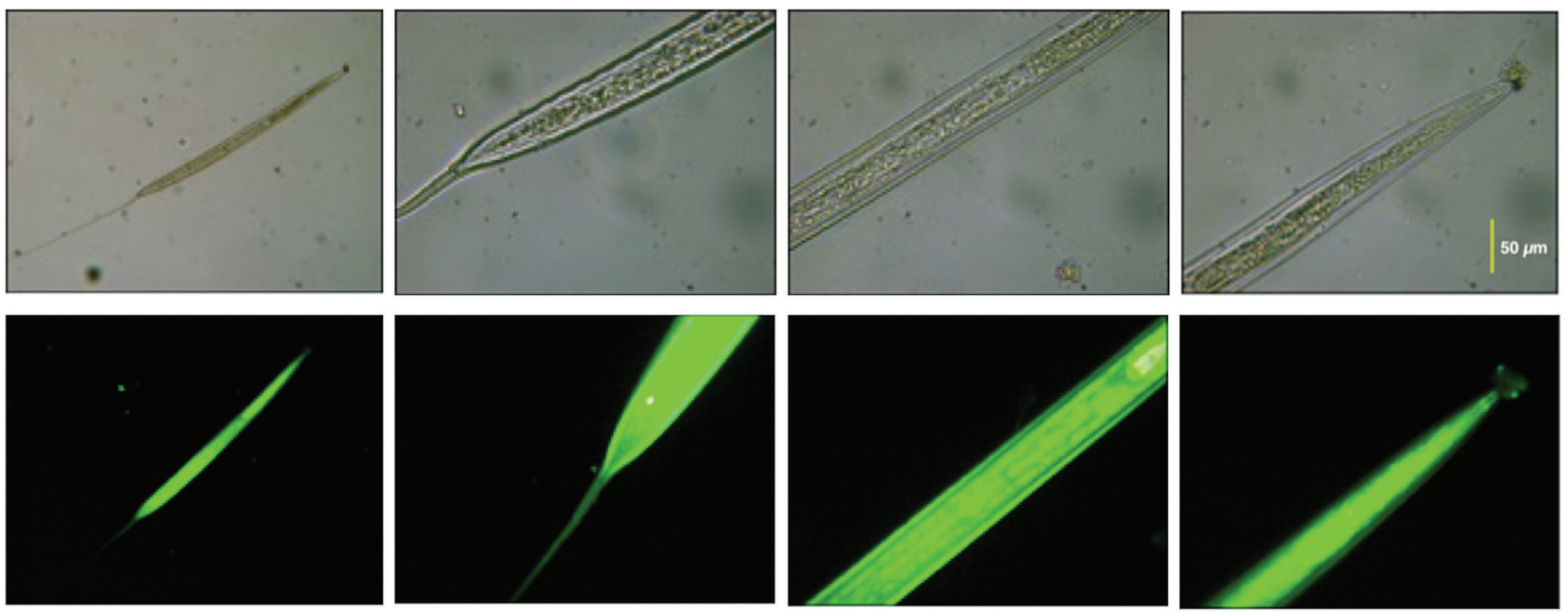

Figure 9. Optical (top) and epifluorescence (bottom) microscopic images of different regions of larvae stained with HB-11 (concentration of $3.3 \mathrm{mM}$ ) at low power (10x, first column) and high power (40x, other columns), using a UV filter and a mercury lamp as a source of excitation. Larvae are $2-8 \mathrm{~mm}$ long by $50-60 \mu \mathrm{m}$.

results show that their photophysical properties are highly influenced by $\mathrm{pH}$ conditions. These dyes have solubilities in water that are satisfactory for applications and studies of biological systems. Both have sulfonic acid functionalities and can be activated and used to conjugate fluorescent dyes to biomolecules. The present dyes were successfully used as new probes by means of direct staining of helminth larvae.

\section{Supplementary Information}

Supplementary information $\left({ }^{1} \mathrm{H},{ }^{13} \mathrm{C}\right.$ APT NMR and infrared spectra of the dyes) is available free of charge at http://jbcs.sbq.org.br as a PDF file.

\section{Acknowledgments}

The authors are grateful for the scholarship and financial support from the Conselho Nacional de Desenvolvimento Científico e Tecnológico (CNPq), Programa EstudantesConvênio de Pós-Graduação (PEC-PG) and the scholarship from the Coordenação de Aperfeiçoamento do Pessoal de Nível Superior (CAPES). The authors also thank the Programa de Pós-Graduação em Ciência dos Materiais (PGCimat) and Institute of Chemistry of the Federal University do Rio Grande do Sul (IQ-UFRGS) for providing laboratory space and analytical support for this work.

\section{References}

1. Barros, H. L.; Stefani, V.; Forensic Sci. Int. 2016, 263, 83.

2. Chen, K.-Y.; Hsieh, C.-C.; Cheng, Y.-M.; Lai, C.-H.; Chou, P.-T.; Chem. Commun. 2006, 4395.
3. Kuila, D.; Kvakovszky, G.; Murphy, M. A.; Vicari, R.; Rood, M. H.; Fritch, K. A.; Fritch, J. R.; Wellinghoff, S. T.; Timmons, S. F.; Chem. Mater. 1999, 11, 109.

4. Catalán, J.; del Valle, J. C.; Claramunt, R. M.; Sanz, D.; Dotor, J.; J. Lumin. 1996, 68, 165.

5. Tsentalovich, Y. P.; Snytnikova, O. A.; Forbes, M. D. E.; Chernyak, E. I.; Morozov, S. V.; Exp. Eye Res. 2006, 83, 1439.

6. Sherin, P. S.; Tsentalovich, Y. P.; Snytnikova, O. A.; Sagdeev, R. Z.; J. Photochem. Photobiol., B 2008, 93, 127.

7. Sherin, P. S.; Grilj, J.; Tsentalovich, Y. P.; Vauthey, E.; J. Phys. Chem. B 2009, 113, 4953.

8. Barros, H. L.; Marques, S. M. T.; Stefani, V.; Vet. Parasitol. 2016, 226, 162.

9. dos Santos, R. C.; Faleiro, N. V. S.; Campo, L. F.; Scroferneker, M. L.; Corbellini, V. A.; Rodembusch, F. S.; Stefani, V.; Tetrahedron Lett. 2011, 52, 3048.

10. Corbellini, V. A.; Scroferneker, M. L.; Carissimi, M.; Rodembusch, F. S.; Stefani, V.; J. Photochem. Photobiol., B 2010, 99, 126.

11. Oliveira, F. F. D.; Santos, D. C. B. D.; Lapis, A. A. M.; Corrêa, J. R.; Gomes, A. F.; Gozzo, F. C.; Moreira, P. F.; de Oliveira, V. C.; Quina, F. H.; Neto, B. A. D.; Bioorg. Med. Chem. Lett. 2010, 20, 6001.

12. Cardoso, M. B.; Samios, D.; Rodembusch, S.; da Silveira, N. P.; Stefani, V.; Photochem. Photobiol. Sci. 2007, 99.

13. Song, X.; Vig, B. S.; Lorenzi, P. L.; Drach, J. C.; Townsend, L. B.; Amidon, G. L.; J. Med. Chem. 2005, 48, 1274.

14. Evans, D. A.; Sacks, C. E.; Kleschick, W. A.; Taber, T. R.; J. Am. Chem. Soc. 1979, 101, 6789.

15. Yamato, M.; Yakugaku Zasshi 1992, 112, 81.

16. Kumar, D.; Jacob, M. R.; Reynolds, M. B.; Kerwin, S. M.; Bioorg. Med. Chem. 2002, 10, 3997. 
17. Navarrete-Vázquez, G.; Yépez, L.; Hernández-Campos, A.; Tapia, A.; Hernández-Luis, F.; Cedillo, R.; González, J.; Martínez-Fernández, A.; Martínez-Grueiro, M.; Castillo, R.; Bioorg. Med. Chem. 2003, 11, 4615.

18. Yildiz-Oren, I.; Yalcin, I.; Aki-Sener, E.; Ucarturk, N.; Eur. J. Med. Chem. 2004, 39, 291.

19. Benazzouz, A.; Boraud, T.; Dubédat, P.; Boireau, A.; Stutzmann, J. M.; Gross, C.; Eur. J. Pharmacol. 1995, 284, 299.

20. Tsopelas, C.; Sutton, R.; J. Nucl. Med. 2002, 43, 1377.

21. Belitz, H.-D.; Grosch, W.; Schieberle, P.; Food Chemistry, $4^{\text {th }}$ ed.; Springer-Verlag: Berlin, 2009.

22. Wilbur, D. S.; J. Nucl. Med. 2003, 44, 1540.

23. Formosinho, S. J.; Arnaut, L. G.; J. Photochem. Photobiol., A 1993, 75, 21.

24. Stefani, V.; Souto, A. A.; Acuña, A. U.; Amat-Guerri, F.; Dyes Pigm. 1992, 20, 97.

25. Ríos, M. A.; Ríos, M. C.; J. Phys. Chem. 1998, 102, 1560.

26. Croce, A. C.; Bottiroli, G.; Eur. J. Histochem. 2014, 58, 2461.

27. Weller, A. H.; Prog. React. Kinet. 1961, 1, 187.

28. Kwon, J. E.; Park, S. Y.; Adv. Mater. 2011, 23, 3615.

29. Rodembusch, F. S.; Leusin, F. P.; Campo, L. F.; Stefani, V.; J. Lumin. 2007, 126, 728

30. Seo, J.-W.; Kim, S.-H.; Park, S.-H.; Park, S.-Y.; Bull. Korean Chem. Soc. 2005, 26, 1706.

31. Santra, S.; Dogra, S. K.; Chem. Phys. 1998, 226, 285.

32. Sinha, H. K.; Dogra, S. K.; J. Chem. Soc., Perkin Trans. 2 1987, 1465.

33. Roberts, E. L.; Dey, A. J.; Warner, I. M.; J. Phys. Chem. A 1997, 110, 5296 .

34. Das, K.; Sarkar, N.; Majumdar, D.; Bhattacharyya, K.; Chem. Phys. Lett. 1992, 198, 443.

35. Rial, A. F.; Piroca, L.; Rosalinski-Moraes, F.; Rev. Acad., Ciênc. Agrár. Ambient. 2010, 8, 341.
36. Melhuish, H. W.; J. Phys. Chem. 1960, 64, 762.

37. Resch-Genger, U.; Rurack, K.; Pure Appl. Chem. 2013, 85, 2005.

38. Stefani, V.; Barros, H. L.; BR1020140309420 2014.

39. Freyermuth, B. H.; US pat. US3491106 A 1970.

40. http://www.arguslab.com/arguslab.com/ArgusLab.html, accessed on September 26, 2018.

41. Roberts, F. H. S.; O'Sullivan, P. J.; Aust. J. Agric. Res. 1950, 1, 99.

42. Padalkar, V. S.; Ramasami, P.; Sekar, N.; J. Lumin. 2014, 146, 527.

43. Woolfe, G. J.; Melzig, M.; Schneider, S.; Dörr, F.; Chem. Phys. 1983, 77, 213.

44. Verdasco, G.; Martín, M. A.; del Castillo, B.; López-Alvarado, P.; Menéndez, J. C.; Anal. Chim. Acta 1995, 303, 73.

45. Santra, S.; Krishnamoorthy, G.; Dogra, S. K.; Chem. Phys. Lett. 1999, 311, 55.

46. Krishnamoorthy, G.; Dogra, S. K.; J. Lumin. 2000, 92, 91.

47. Krishnamoorthy, G.; Dogra, S. K.; J. Lumin. 2000, 92, 103.

48. Dick, P. F.; Coelho, F. L.; Rodembusch, F. S.; Campo, L. F.; Tetrahedron Lett. 2014, 55, 3024.

49. Zaater, S.; Bouchoucha, A.; Djebbar, S.; Brahimi, M.; J. Mol. Struct. 2016, 1123, 344.

50. Govindarajan, M.; Periandy, S.; Carthigayen, K.; Spectrochim. Acta, Part A 2012, 97, 411.

51. Ravikumar, C.; Joe, I. H.; Jayakumar, V. S.; Chem. Phys. Lett. 2008, 460, 552.

52. Syetov, Y.; J. Fluoresc. 2013, 23, 689.

53. Sinha, H. K.; Dogra, S. K.; Chem. Phys. 1986, 102, 337.

54. Roohi, H.; Hejazi, F.; Mohtamedifar, N.; Jahantab, M.; Spectrochim. Acta, Part A 2014, 118, 228.

55. Cedillo, A.; Contreras, R.; Galván, M.; Aizman, A.; Andrés, J.; Safont, V. S.; J. Phys. Chem. A 2007, 111, 2442.

Submitted: July 18, 2018 Published online: September 28, 2018 